
Editor

With 491 Figures and 26 Tables

Christopher K. Starr

\title{
Encyclopedia of Social Insects
}


$9 \quad$ Editor

Christopher K. Starr

Independent Researcher

Caura Village, Trinidad and Tobago

ISBN 978-3-030-28101-4

ISBN 978-3-030-28102-1 (eBook)

ISBN 978-3-030-28103-8 (print and electronic bundle) https://doi.org/10.1007/978-3-030-28102-1

\section{(C) Springer Nature Switzerland AG 2021}

This work is subject to copyright. All rights are reserved by the Publisher, whether the whole or part of the material is concerned, specifically the rights of translation, reprinting, reuse of illustrations, recitation, broadcasting, reproduction on microfilms or in any other physical way, and transmission or information storage and retrieval, electronic adaptation, computer software, or by similar or dissimilar methodology now known or hereafter developed.

The use of general descriptive names, registered names, trademarks, service marks, etc. in this publication does not imply, even in the absence of a specific statement, that such names are exempt from the relevant protective laws and regulations and therefore free for general use.

The publisher, the authors, and the editors are safe to assume that the advice and information in this book are believed to be true and accurate at the date of publication. Neither the publisher nor the authors or the editors give a warranty, expressed or implied, with respect to the material contained herein or for any errors or omissions that may have been made. The publisher remains neutral with regard to jurisdictional claims in published maps and institutional affiliations.

Cover illustration: After a heavy rain, a Synoeca cyanea worker removes water from the nest envelope. Photo $\subset$ Alex Wild.

This Springer imprint is published by the registered company Springer Nature Switzerland AG. The registered company address is: Gewerbestrasse 11, 6330 Cham, Switzerland 
The Biblical proverb, Go to the ant, thou sluggard; consider her ways, and be wise, epitomizes human attitude toward social insects throughout much of history. The societies of insects have inspired us to draw lessons, issue injunctions, influence politics, and formulate moral principles. And yet, much of this has been based on partially correct, incorrect, and sometimes dead-wrong ideas about the biology of social insects.

A particularly embarrassing example concerns the uncritical assumption, held by almost everyone until as recently as early eighteenth century, that the queen of the honey bee colony must be a king, and, to make matters worse, the use of that mistaken identity to deprive women of a place in public and political life. The "leader of the beehive" is neither a male nor indeed a leader, in almost any sense of the term. Most complex behavior in social insects is selforganized in a decentralized, bottom-up manner, with little scope or evidence of top-down control. The metaphoric transfer of power from the males to the females and from the royalty to the subjects is the result of two centuries of the scientific study of insect societies presented in this encyclopedia.

Social insects - ants, bees, wasps, termites, and a few aphids, thrips, and beetles - account for about $2 \%$ of the approximately one million species of insects described so far. Despite this modest taxonomic representation, social insects, especially ants and termites, are among the most evolutionarily successful and ecologically dominant species on earth, estimated to comprise up to three quarters of the total animal biomass in some tropical forests. They are found in virtually all land habitats worldwide where insects abound.

The Earth is estimated to harbor some 10 trillion ants that together weigh about as much as all 7.4 billion humans. The success of social insects is attributed to their ability to cooperate and form large colonies, with division of labor, communication, and the propensity for individual members to sacrifice their reproductive success and even their lives in the interests of the colony. Equally important is their ability to build elaborate nests and achieve impressive climate control. With few exceptions, members of a colony are not a clone, but they have nevertheless evolved elaborate mechanisms for conflict management.

One important reason for our interest in social insects is that we depend on some of them for our welfare. A third of our agriculture and food production, especially fruits, vegetables, and nuts, crucially depends on the pollination services rendered by honey bees and bumble bees (as well as many solitary 
bees), the global economic value of which has been estimated at US\$577 billion annually. In recent decades, bee populations have declined worldwide and therefore their services have been under great threat, endangering our food security and global peace, ironically caused by over-exploitation and mismanagement.

The blame for the havoc caused by importing the Varroa destructor mite to regions of the world where honey bees are not adapted to co-exist with it, and more generally for the so-called Colony Collapse Disorder, can be laid straight at our doorstep. We have unsuccessfully attempted to make honey bees live life in the fast lane, under crowded conditions, with frequent transportation over thousands of kilometers, exposed to multiple pesticides, faced with diminished diversity and abundance of nectar and pollen-producing plants, and forced to invest more in honey production than in colony maintenance and reproduction. We erroneously believe that we know best how honey bees should organize their lives and have only recently begun to understand how millions of years of evolution have shaped their sustainable lifestyles in the wild. It is time we learn from the bees rather than attempt to teach them. This will need learning much more than we know already and, more importantly, disseminating the little knowledge that we already have as widely as possible.

We are also interested in social insects because we fear them. Leafcutter ants have been important to the economy of Latin America since historical times to the present, being the most important herbivores in the region, devastating more vegetation than any other animals and causing destruction worth billions of dollars. The battle between humans and leafcutter ants is a unique one - the ants steal the products of our agriculture not just to feed on them but to use as raw material to sustain their own agriculture - making them the kind of enemies that demand our respect and admiration. Leafcutter ants have been practicing the cultivation of fungi in their gardens for over 50 million years. The secrets of their success in achieving sustainable agriculture, some of them worthy of emulation, are only now being discovered.

The fire ant Solenopsis invicta, innocuous in its native South America, has become famously invasive in Southeastern United States, Australia, China, and Taiwan. It is a major health hazard in the USA requiring the expenditure of over $\$ 5$ billion annually toward damage control, suppression, and medical treatment. In a failed attempt to breed a honey bee that combines the industriousness of the African bees with the gentleness of the European bees, scientists inadvertently produced and released, and/or let escape, a hybrid that is highly defensive toward humans and native bees. This hybrid bee spread through South and Central America in the 1990s at a rate of 300-500 km/year, reaching densities of 6 colonies per $\mathrm{km}$ that translate to about a trillion bees. Some termites are another kind of serious social insect pest, damaging buildings, wooden structures, and crops and requiring billions of dollars in expenditures, while also bringing about significant environmental pollution on account of the chemicals used to control them.

Beyond the love-hate relationship, most of us will admit to a sense of wonder and amazement at what our objects of study are capable of. Ant, bee, and wasp queens gather sperm from their mates, store and nourish them in their bodies for years and even decades, and then use them to make 
daughters, or not use them, to make sons, giving them complete control over the sex of their offspring. The pheromone trails of ants guide them to distant locations of food and back to their nests.

When ants lacking trail pheromones have to relocate their nests, some of them spontaneously emerge as leaders carrying or tandem-running their nestmates to the new nest site. When ants, bees, and wasps walk or fly out in meandering paths, they continuously update information about their linear and angular displacement using the sun and other celestial cues, polarized light, and landmarks, after which they can walk or fly straight back to their nests.

Honey bees go a step further and communicate the distance and direction to food sources by means of a dance language, the discovery of which brought a Nobel Prize to social insect research. Honey bees also make the ultimate altruistic sacrifice in defense of their colonies - because they are unable to withdraw their barbed stings when attacking humans or other vertebrates, so that their abdomens rupture, fatally. The Argentine ant Linepithema humile forms supercolonies with billions of workers spread over $6000 \mathrm{~km}$ of coastline from Italy to Spain.

In addition to immune defenses of individual members of their colonies, social insects have a whole tool-kit of social immunity. The most remarkable feature may be the fine balance they achieve between their first line of defensemaintaining nest hygiene to prevent the spread of infection - and a final line of defense by killing and removing infected members.

Social insects have been at the forefront of the development of evolutionary theory. Charles Darwin worried about the "neuters" (i.e., workers) as a potential "insuperable difficulty" for his theory of evolution by natural selection. $\mathrm{He}$ proposed a way around it that is the forerunner of the modern theory of group selection. JBS Haldane, while contemplating how many brothers would he have to save from drowning in order to make it worthwhile to sacrifice his life, quickly turned his attention to honey bees and realized they might be more prone to sacrificial behavior.

William D. Hamilton drew inspiration from social insects, especially the social wasps that he observed in Brazil, to develop his theory of inclusive fitness, also known as kin selection. Recent controversies regarding the relative roles of individual, kin, and group selection have led to the development of multilevel selection theory. Because the evolution of altruism by natural selection remains a major unsolved paradox, social insects are still in the front lines of the elaboration of evolutionary theories, their controversies and their resolution, and will thereby throw much light on the rest of the living world.

Complex social behavior, including communication, transport, and the mind-boggling nest architecture so characteristic of many social insects, result not from superior conventional intelligence of individual members of their societies but through a process of decentralized self-organization - individual insects follow simple local rules that nevertheless result in the emergence of complexity. This knowledge has most surprisingly impacted science and technology well outside the social insect world and indeed outside biology.

The development and application of ant, bee, wasp, and termite-inspired procedures and algorithms in computer science, transportation, 
telecommunications, the Internet, and robotics has been an unforeseen consequence of curiosity-driven research on social insects and their ways of solving their own day-to-day problems. To take another example, ant and honey bee queens can provide new insights for the study of ageing and senescence. While ant and honey bee workers have a natural life span in the order of a few weeks, their queens, who develop from the same genomes, can live for years and sometimes for decades. Even among honey bee workers, summer bees age faster than winter bees and forager bees faster than nurse bees. Their long and flexible life spans make social insects attractive and as yet poorly explored model systems for understanding the nutritional, physiological, and molecular modulation of ageing and senescence.

Social insect science is poised to make even greater contributions to the growth of knowledge and technology in many different areas of human activity. To facilitate this, we need to provide easy access to our growing understanding of the world of insect societies to a wide audience who may never care to call themselves biologists, let alone entomologists. The Encyclopedia of Social Insects is designed to fill this very need. In a decentralized, self-organized manner, befitting the insect societies, the International Union for the Study of Social Insects (IUSSI) has undertaken as a community project the production of this compendium of our current knowledge about social insects, as well as social spiders, the result of which you now have before you. Perhaps it's time to rephrase the Biblical proverb and say: Go to the Encyclopedia of Social Insects, thou curious one; consider its contents, and be enlightened.

Centre for Ecological Sciences

Raghavendra Gadagkar

Indian Institute of Science

Bangalore, India 